\title{
Exploring Nurses' Perception of Antibiotic Use and Resistance: A Qualitative Inquiry
}

\author{
Muhammad Anwar' \\ Abdul Raziq ${ }^{2}$ \\ Maryam Shoaib ${ }^{3}$ \\ Nosheen Sikandar Baloch ${ }^{4}$ \\ Shanaz Raza ${ }^{5}$ \\ Bisma Sajjad ${ }^{5}$ \\ Nabila Sadaf ${ }^{5}$ \\ Zaffar lqbal ${ }^{6}$ \\ Rabia Ishaq' \\ Sajjad Haider' \\ Qaiser Iqbal' \\ Nafees Ahmad' \\ Naheed Haque' \\ Fahad Saleem (ID) \\ 'Faculty of Pharmacy \& Health Sciences, \\ University of Balochistan, Quetta, \\ Pakistan; ${ }^{2}$ Department of Statistics, \\ University of Balochistan, Quetta, \\ Pakistan; ${ }^{3}$ Sandeman Provincial Hospital, \\ Quetta, Pakistan; ${ }^{4}$ Bolan Medical College, \\ Quetta, Pakistan; ${ }^{5}$ Sardar Bahadur Khan \\ Womens' University, Quetta, Pakistan; \\ ${ }^{6}$ Health Department, Government of \\ Balochistan, Quetta, Pakistan
}

\begin{abstract}
Purpose: Quality use of antibiotics and the development of antibiotic resistance is a global catastrophe. In the conceptual context, the phenomenon is correlated with the healthcare practitioners' understanding of antibiotic use and resistance. Therefore, the study aimed to highlight nurses' perception of antibiotic use and resistance at a public healthcare institute in Quetta City, Pakistan.
\end{abstract}

Respondents and Methods: By using a semi-structured interview guide through the phenomenology-based approach, in-depth, face-to-face interviews were conducted. Nurses practicing at the surgical and medical units of Sandeman Provincial Hospital (SPH), Quetta, were approached for the study. All interviews were audio-taped, transcribed verbatim, and were then analyzed for thematic contents by the standard content analysis framework.

Results: Although the saturation was reached after the 13th interview, an additional two were interviewed for absolute validation. Content analysis revealed five major themes: (1) defining antibiotics and antibiotic resistance, (2) antibiotic use: awareness and concern, (3) antimicrobial resistance: awareness and concern, (4) responding to antibiotic use and resistance, and (5) barriers to quality use of antibiotics and prevention of antibiotic resistance. Even though the understanding of nurses regarding antibiotic use and resistance was promising, certain apprehensions were also observed. The respondents were aware of the critical situation and provided valuable insights that can offer significant input while promoting the quality use of antibiotics in a developing country.

Conclusion: While the perception towards antibiotics appeared positive, potential areas of concern and contributing factors regarding antibiotic resistance were also identified. Importantly, nurses too highlighted possible solutions to address the issue of irrational antibiotic use and the development of antibiotic resistance.

Keywords: resistance, quality use of antibiotics, nurses, perception

\section{Introduction}

Globally recognized as "life-saving drugs", antibiotics are the decisive choice for the treatment of infectious diseases. ${ }^{1}$ Their impact on global health can be reflected by their continual usage for decades that resulted in decreased morbidity and mortality. ${ }^{2}$ Since their birth, antibiotics are serving as a critical weapon in fighting against deadly bacterial infections either by killing the bacterial pathogen or by ceasing their rapid growth. ${ }^{3}$ However, despite being one of the most efficient classes of drugs in treating infections, misuse of antibiotics is becoming a major concern for health authorities around the world. ${ }^{4}$

It is generally believed that antimicrobial resistance develops when bacterial pathogens are unnecessarily or abusively subjected to antibiotic therapy. ${ }^{5}$ However, bacteria can choose multiple pathways in developing resistance even with
Correspondence: Fahad Saleem Faculty of Pharmacy \& Health Sciences, University of Balochistan, Quetta, Pakistan

Tel +923458326545

Fax +92819211288

Email fahaduob@gmail.com 
rationalized antibiotic use. ${ }^{6}$ Once the bacteria become resistant, it may be transferred to the coming generations when bacteria divide, making the pathogen resistant to the particular therapy. ${ }^{7}$ Although resistance is a natural phenomenon the pathogens are evolving themselves accordingly whenever they are exposed to antibiotics. ${ }^{8}$ However, during the last 80 years, abuse of antibiotics by humans resulted in the prevalence of antibiotic resistance in the whole environment. ${ }^{9}$ Especially in the developing countries, antibiotics are being misused in massive amount even for the common cold, flu, and viral infections. ${ }^{10,11}$ Thus, developing resistance towards almost all classes of antibiotics has become a global threat including Pakistan. $^{12,13}$ Between the years 2000-2010, antibiotic consumption is reported to be increased by $36 \%$ among humans. ${ }^{14}$ Some studies suggest that if the development of resistance is not halted, this could lead to more than 10 million deaths every year by $2050 .{ }^{15}$ There are various reasons for antibiotic misuse and are attributed to various levels. ${ }^{16-18}$

Poor knowledge of the healthcare professionals regarding quality use of antibiotics, ${ }^{19}$ lack of antibiotic stewardship programs for healthcare professionals including nurses, ${ }^{20}$ self-medication by the general public due to insufficient knowledge ${ }^{21}$ and financial crisis especially in the developing countries are the main contributing factors towards the development of antimicrobial resistance. ${ }^{22}$ Also, the patient expectation for antibiotics is another factor influencing GP antibiotic prescribing behaviours. ${ }^{23}$ Within this context, Cole in 2014 reported that $55 \%$ of the GPs in the UK felt the pressure of the patients to prescribe antibiotics, even if they were not sure that they were necessary. ${ }^{24}$ However, due to knowledge deficit, the patient usually places pressure on the prescriber for antibiotic therapy which leads to unnecessary antibiotic consumption. ${ }^{25}$

Among all healthcare professionals, nurses are an integral component of the healthcare system. Nurses have direct interaction with the patients during the drug administration process and play an important role in ensuring quality use of medicines. Therefore, the objective of the present study was to seek understanding, perception, and practices of nurses about antibiotic use and resistance in Pakistan.

\section{Methods}

\section{Study Design and Settings}

We opted for a qualitative study design for manifold reasons. This method is flexible and consents to a detailed exploration of respondents' attitudes, experiences, and intentions. ${ }^{26,27}$ Moreover, qualitative studies generate a wide range of ideas and opinions that individuals carry about issues, as well as divulge viewpoints and differences among groups. ${ }^{28,29}$ However, most importantly, qualitative methods fill the gaps left unexposed by survey-based research precisely when it comes to underdiscovered research areas. ${ }^{30}$ Therefore, in line with the objectives of this study, a qualitative design was an unmatched choice for inductive approaches aimed at generating concepts and hypotheses which have far more potential for research than any other models. ${ }^{31}$

The study site was the surgical and medical units of Sandeman Provincial Hospital (SPH), Quetta. Established in 1939 and located in the center of the City, SPH is 800bedded tertiary care, teaching institute. The hospital provides both inpatients as well as outpatient services. Additionally, being the largest public healthcare institute of Quetta City, SPH is well established, and all facilities and modern machinery are available. Furthermore, patients typically prefer to approach SPH because of affordability, and hence SPH is the institute of choice for the majority of the residents. ${ }^{32}$

\section{Study Participants, Sampling, and Criteria}

Registered nurses stationed and practicing at the surgical and medical units and consenting to participate in the study were approached for the interviews. Antibiotics are frequently prescribed in the surgical and medical units of SPH (personal observation), therefore the snowball sampling method was the apparent choice for this study. ${ }^{33}$ Nurses on rotation, stationed in the units as part-timers and not willing to participate were excluded.

\section{The Interview Guide (Pilot Study)}

The research team constructed a semi-structured interview guide after an extensive literature review, ${ }^{34-38}$ through an expert panel discussion, and experience sharing. ${ }^{39-41}$ The guide was established with widely framed, open-ended questions that gave enough opportunities to the respondents. In parallel, nurses were also encouraged to provide their narratives and to share further information relevant to antibiotic use and resistance.

The guide was constructed in the English language and was translated into Urdu (National language of Pakistan) by an independent linguistic expert. The translated guide was back-translated into English to avoid discrepancies by another independent translator. ${ }^{42}$ The guide was piloted 
with four nurses to ensure that topics to be discussed were at the level that respondents would comprehend with ease. The preliminary data and conclusions confirmed that the discussion topics were enough and appropriately phrased to answer research questions and to minimize validity and reliability threats. Nurses involved in the pilot study were not recruited for the main study to avoid exposure/participant bias.

\section{Interview Procedure, Data Collection, and Analysis}

The first author conducted the interviews in the nursing rooms. All interviews were conducted in Urdu as it was easier for the respondents. Participants were briefed about the study objectives before the interviews. A debriefing session was again conducted at the end of the discussion. The interviews started with an ice-breaking session. Probing questions were asked in between conversations to clarify the meanings of responses and to gain insight into the topic being discussed.

Each interview was audio-recorded that lasted for approximately half an hour. To draw in-depth views, the freedom to express additional reviews and comments was given to the nurses. The second author acted as an observer while the third author assisted in monitoring the field notes, facial expressions, and body language that complemented the audio recordings. Interviews were conducted until thematic saturation was reached. ${ }^{43,44}$ The research team analysed the recordings (verbatim) and later arranged an informal gathering where individual nurses were presented with the finalized interview scripts. ${ }^{45}$ This was performed to ensure the confidentiality of the responses. Nurses were asked for confirmation of the precision and accuracy of words, ideas, and jargon used during the script analysis. Once confirmed, the transcripts were translated into English by another independent translator for thematic content analysis. The collected data were subjected to the determination of coding categories that was followed by coding of the contents. The legitimacy and consistency were assured and data was formally analyzed. ${ }^{46,47}$ NVivo ${ }^{\circledR}$ was used for coding and analysis through iterations ${ }^{48}$ and inconsistencies were resolved through mutual consensus. All emerging themes and subthemes were discussed among the research team for accuracy and were presented for data inference and interpretation.

\section{Ethical Approval}

The institutional review board at the Faculty of Pharmacy \& Health Sciences, University of Balochistan approved the study protocol (UoB/Reg:/GSO/67). Written consent was taken from the respondents before the individual semistructured interviews. The nurses were introduced to the nature of the research before the beginning of the interviews, were made secure of the confidentiality of their responses and their right to withdraw from the study. Nurses also provided informed consent to have their anonymized responses published, in accordance with the Declaration of Helsinki.

\section{Results}

\section{Demographic Characteristics of the Study Respondents}

Fifteen nurses were interviewed, and all were females. A majority $(10 ; 66.6 \%)$ of the nurses were practicing as a staff nurse while $8(53.3 \%)$ had a Bachelor of Science in Nursing. Thirteen (86.7\%) respondents had an overall nursing experience of fewer than ten years, as shown in Table 1.

Thematic content analysis resulted in five major themes (Figure 1). The themes and sub-themes are discussed as under:

\section{Theme I: Defining Antibiotics and Antibiotic Resistance}

Scientifically speaking, our study respondents clearly defined "antibiotics". The finding is encouraging because

Table I Demographic Characteristics of the Respondents

\begin{tabular}{|l|c|}
\hline Characteristics & Frequency (Percentage) \\
\hline Age (years) & $7(46.7)$ \\
$18-27$ & $8(53.3)$ \\
$28-37$ & \\
\hline Education & $2(13.3)$ \\
Nursing diploma & $8(53.3)$ \\
Bachelor of Science in Nursing & $5(33.3)$ \\
Master of Science in Nursing & \\
\hline Nursing experience (years) & $13(86.7)$ \\
I-10 & $2(13.3)$ \\
$>$ I0 & \\
\hline Current position & $10(66.6)$ \\
Staff nurse & $2(13.3)$ \\
Senior nurse & $3(20.0)$ \\
Head nurse & $8(53.4)$ \\
\hline Practicing department & $7(46.6)$ \\
Surgical unit & \\
Medical unit & \\
\hline
\end{tabular}




\begin{tabular}{|c|c|c|c|}
\hline \multicolumn{4}{|c|}{ Theme 1: Defining antibiotics and antibiotic resistance } \\
\hline \multicolumn{4}{|c|}{ Theme 2: Antibiotic use: awareness and concern } \\
\hline $\begin{array}{c}\text { Sub theme 2(a): } \\
\text { Antibiotic use in the hospital: } \\
\text { awareness }\end{array}$ & $\begin{array}{c}\text { Sub theme 2(b): } \\
\text { Antibiotic use in the community: } \\
\text { awareness }\end{array}$ & $\begin{array}{l}\text { Sub theme 2(c): } \\
\text { Antibiotic use in the hospital: } \\
\text { concerns }\end{array}$ & $\begin{array}{l}\text { Sub theme 2(d): } \\
\text { Antibiotic use in the community: } \\
\text { concerns }\end{array}$ \\
\hline \multicolumn{4}{|c|}{ Theme 3: Antimicrobial resistance: awareness and concern } \\
\hline \multicolumn{2}{|c|}{$\begin{array}{l}\text { Sub theme 3(a): } \\
\text { Antibiotic resistance: awareness }\end{array}$} & \multicolumn{2}{|c|}{$\begin{array}{c}\text { Sub theme 3(b): } \\
\text { Antibiotic resistance: concerns }\end{array}$} \\
\hline \multicolumn{4}{|c|}{ Theme 4: Responding to antibiotic use and resistance } \\
\hline \multicolumn{4}{|c|}{ Theme 5: Barriers to quality use of antibiotics and prevention of antibiotic resistance } \\
\hline \multicolumn{2}{|c|}{$\begin{array}{l}\text { Sub theme 5(a): } \\
\text { Patient-related barriers }\end{array}$} & \multicolumn{2}{|c|}{$\begin{array}{c}\text { Sub theme 5(b): } \\
\text { Institutional-related barriers }\end{array}$} \\
\hline
\end{tabular}

Figure I Schematic presentation of themes and sub themes identified during data analysis.

evidence-based information integrates clinical expertise with the best available evidence. ${ }^{49}$ This also justifies the actual needs of the healthcare system and patients' preferences. $^{50}$ Additionally, evidence-based information delivers guidance and establishes best practices in the practicing field.

Antibiotics are medicines that are used to kill the bacteria. Some antibiotics decrease the growth of the bacteria by inhibiting their reproduction. These are the drugs of choice against bacterial infections. (Nurse 1)

Increased frequency of antibiotic resistance is a major medical concern. In line with what is stated above; nurses also had a good understanding of antibiotic resistance. This reflected their understanding of the phenomenon that can eventually help in the delivery quality of nursing care. ${ }^{51}$

When antibiotics are unaffected during treatment (do not work against bacteria), it is called antibiotic resistance. This happens because of the over-use of antibiotics, bacterial mutations, and substantial use of antibiotics in agriculture and among animals (like poultry and livestock). (Nurse 3)

\section{Theme 2: Antibiotic Use: Awareness and Concern}

Sub Theme 2 (A): Antibiotic Use in the Hospital: Awareness

The nurses were inquired about antibiotic use at their practice sites. Because of the in-patient settings, frequent use of antibiotics was reported by the study respondents. Again, because of the patients being admitted at the wards, parenteral antibiotics were prescribed when compared with the oral. While talking specifically about the types of antibiotics, 3rd generation cephalosporins, fluoroquinolones, glycopeptides, carbapenem, and Beta-lactam/betalactamase inhibitors were the most common antibiotics used.

Parenteral antibiotics are very commonly prescribed. For the outpatients, oral antibiotics are preferred (if available in the store). We are using Meropenem and Vancomycin to a larger extent compared to other antibiotics. As I have observed, every third prescription contains these two drugs. (Nurse 7)

\section{Sub Theme 2 (B): Antibiotic Use in the Community: Awareness}

Because of weak legislation and lack of an effective surveillance system, antibiotics are freely available at the medical stores (community pharmacies) of the City. Additionally, no prescription is required, and a person can get any type of medicine (including antibiotics) from the medical stores. Nurses were also aware of this free availability of antibiotics and explained their understanding in a detailed manner.

You just name it (antibiotic), and you will get it from the medical stores. From brands to generics, all antibiotics are freely available. Unfortunately, policymakers have never 
taken serious actions against the sale of antibiotics. Selling medicine in the City is a business and not healthcare. (Nurse 6)

\section{Sub Theme 2 (C): Antibiotic Use in the Hospital: Concerns}

Certain reservations were reported when concerns towards antibiotic use in the hospital were inquired. Summarizing the reservations, the limited availability of antibiotics in the hospital was a significant concern. A possible reason for the limited availability is attributed to the challenges faced by the healthcare system of Pakistan. Although the healthcare system of the country has shown improvement in recent years, it is still faced with increasing population demands, poor infrastructure, and funding. ${ }^{52}$ For that very reason, a limited amount of antibiotics (both in terms of quantity and category) are available at the hospitals. Thus, practitioners have no choice but to prescribe available antibiotics.

There are a few options when it comes to prescribing antibiotics. When patients are admitted, antibiotics are prescribed based on availability and not based on his/her condition. At times he/she is prescribed that are not therapeutically needed, but we do not have other options. We cannot let the patient suffer or die! (Nurse 13)

\section{Sub Theme 2 (D): Antibiotic Use in the Community: Concerns}

The free availability of antibiotics in the community was the foremost concern of our study respondents. This convenience promotes self-medication and irrational use of antibiotics that result in economic and therapeutic loss to society. Additionally, this encourages the development of antibiotic resistance. Our respondents believed that frequent antibiotic use in our community is a considerable matter when compared to antibiotic use in the hospital and practice sites.

Imagine going to a medical store and buying 2-3 tablets/ capsules of amoxicillin, erythromycin, etc. Furthermore, there is no concept of the recommended dose and duration of therapy. There is no diagnosis and no prescription and we are only prompting irrational use and developing antibiotic resistance. (Nurse 2)

\section{Theme 3: Antimicrobial Resistance: Awareness and Concern} Sub Theme 3 (A): Antibiotic Resistance: Awareness As discussed earlier, nurses precisely defined antibiotic resistance and hence had a clear idea of what antibiotic resistance is. Better awareness and proper knowledge raise responsiveness of accountability and improve care as nurses are aware of the best knowledge or evidence to use in practice.

Because sometimes therapy is stopped, or the course (duration) is not completed, self-medication, use of heavy (high end) antibiotics or leftovers, all can result in antibiotic resistance. There can be other reasons also, but the issue is disturbing and needs immediate attention. (Nurse 11)

\section{Sub Theme 3 (B): Antibiotic Resistance: Concerns} "Certain bacteria have developed resistant to a majority of available antibiotics", and that was the most serious concern of healthcare professionals (nurses). Respondents of our study had grave apprehensions and did share their concerns during the interviews. The development of antibiotic resistance (a concerning threat; Nurse 5) is resulting in sufferings, deaths, and economic loss, which are threatening the healthcare systems, patients, and society. Respondents also perceived antimicrobial resistance as a major problem within their practice, since the infections they managed were generally non-responsive to firstand second-line antibiotics, and they have experience treatment failure with these agents.

The condition is threatening. We had a patient (older woman, 60 years) admitted in the ward. We used four different types of antibiotics before we received the sensitivity test. We found out that she was resistant to all antibiotics that we have. The patient died the next day, putting a question for us. What will happen in future if we keep on receiving such patients? Frankly, we have no answer. (Nurse 9)

Another nurse informed that

roughly a year ago, we used Ciprofloxacin for typhoid fever. It is no more effective, and now we are using Meropenem. I can give more examples where antibiotics are no more effective. It is scary to imagine the day when Meropenem, Vancomycin, and Tazobactam (etc.) will stop working too. We are seriously concerned, and we need a solution as soon as possible.

\section{Theme 4: Responding to Antibiotic Use and Resistance}

Usually, once the scale of the problem is identified (or is adequately known), it is crucial to categorize the response 
in reply to the problem. This helps in planning and developing remedial schedules or interventions that can help in overcoming the problem. Therefore, it was important to highlight respondents' views on antibiotic use and resistance in their practice settings. Conflicting views were observed when the response to antibiotic use was investigated. Four of the respondents agreed that because antibiotics are prescribed by the physicians, they are unable to respond to the antibiotic use in the hospital. One of the nurses mentioned that

I am responsible for drug administration, advocacy, and patient care. As I see it, interfering in the prescribing process is unethical, and I am also not allowed to do so.

On the contrary, nurses were observed consulting and discussing the therapy with the prescribers and issues related to antibiotic use. This assistance helped the physicians in promoting the quality use of antibiotics.

Once an antibiotic is prescribed, it is us (nurses) that will administer it to the inpatients. At times we notice that the prescribed antibiotic is not rational (or is not needed) or has other issues. In such a condition, we discuss the subject with the prescriber to make sure that the medications are prescribed and administered without making mistakes. (Nurse 14)

Moreover, the nurses' response to the development of antibiotic resistance was also sought. Almost all nurses shared the same opinion and seemed deserted while responding to antibiotic resistance. Lack of a surveillance system and unable to identify how resistance is identified were the primary reasons while responding to antibiotic resistance. Among apprehensions, we identified the nonresponsiveness to antibiotic resistance as a significant concern among the study respondents.

From experience, I can tell that this antibiotic is resistant to that disease. However, I have no idea what to do next and how to respond to the development of antibiotic resistance. We have heard a lot about antibiotic resistance, but it is all in books, news, seminars, and nothing in practice. This will get worse, and we cannot do anything to stop it. (Nurse 10)

\section{Theme 5: Barriers to Quality Use of Antibiotics and Prevention of Antibiotic Resistance}

Prescribing antibiotics based on established guidelines, antibiotic susceptibility testing, and clinical response can slow down the frequency of antibiotic resistance. In parallel, the surveillance of antibiotic availability in the community settings and restrictive self-medication is also needed. However, antibiotic resistance can only be controlled and minimized by the determined efforts of all members of society for ensuring the continued efficiency of antibiotics. Therefore, identification of a potential barrier in promoting the quality use of antibiotics and minimizing the development of antibiotic resistance is imperative. Within this context, several barriers were identified by the study respondents while addressing the quality use of antibiotics and the development of antibiotic resistance and will be discussed consequently.

\section{Sub Theme 5 (A): Patient-Related Barriers}

Self-medication, using leftover antibiotics, the expectation of antibiotics during the consultation, and demanding an antibiotic were identified as the key barriers to quality use of antibiotics and antibiotic resistance. These findings are not strange as these barriers are identified in the literature. ${ }^{53,54}$ Yet, patient-related factors still pose a more significant threat to the development of antibiotic resistance and must be on the priority list of the policymakers while designing related interventions.

Patients are always demanding; they ask for antibiotics. When refused, they will purchase it from medical stores. Worst, they will redistribute them among their family members and friends, and this chain goes on. You want to control it, strictly instruct the medical stores not to sell antibiotics without prescription. (Nurse 1)

Continuing with the patient-related factors, the urgency of getting a cure by using antibiotics was also highlighted as a barrier in the quality use of antibiotics. Understandably, disease(s) are unpleasant, and the need for a quick recovery is natural; however, it is irrational to use medicines for conditions that are not meant to be used. Our respondents believed that at times patients tend to use antibiotics (in high doses or even not recommended) for their condition, considering that it will pace up the recovery process. This absurd use of antibiotics was also highlighted as a reason for antibiotic resistance.

While being questioned (by physicians or nurses), using an antibiotic before coming to the hospital is usually reported by the patients. The reason is always the same (it cures everything). This is an issue that we are facing almost daily. Don't you think this is causing antibiotic resistance? (Nurse 4) 


\section{Sub Theme 5 (B): Institutional-Related Barriers}

The majority of the respondents also emphasized certain institution-related deficiencies and limitations as a barrier towards quality use of medication and antibiotic resistance. The most commonly reported barrier was the limited number of antibiotics available at the central pharmacy. As with other public healthcare institutes, medicines in SPH are purchased on annual basis. The demand for medicines is provided by the departments of the hospital-based on their annual consumption. However, because of the financial constraints faced by the healthcare system, medicines are purchased but in a limited quantity. Therefore, a shortage of medicines is often reported at the end of the fiscal year. Consequently, availability is attained by reducing the quantity and type of medicines (when one class of antibiotics is available, the other class is inevitably rejected). However, this limits the choice for the prescribers, and they must prescribe what is available at the hospital.

For the inpatients, I can count the available antibiotics on fingertips. Therefore, if it is meningitis, UTI, or cholera (etc.), the patients will be prescribed the same antibiotics. What else can we do? This is a public hospital and people cannot afford medications purchased from outside. (Nurse 5)

In clinical practice, the selection of antibiotics is based on consulting the developed guidelines and performing a culture sensitivity test. Ideally, antibiotic therapy is based on the determination of the etiological agent and its relevant antibiotic sensitivity. Empirical treatment is often started before sensitivity reports are available because it is not wise to delay the treatment because of the seriousness of the disease. Another barrier reported by the respondents was the limited sensitivity facility available at the hospital. Therefore, without sensitivity reports being available, empirical treatment is often practiced and, hence promoting antibiotic resistance.

Hospital' capacity of sensitivity analysis is very limited. If we send the sample outside, it is costly, and patients are unable to afford it. There is no option available other than to continue using antibiotics that are being used for the same diseases. (Nurse 12)

Another respondent (Nurse 4) said that "we are aware of the guidelines and protocol for antibiotic selection. The question is about availability (in the hospital) that is poor.
Even if we follow the guidelines, how would we prescribe the antibiotic that is not available in the hospital?"

\section{Discussion}

Rational use of antibiotics is indispensable to minimize the burden of antibiotic resistance. Within this context, nurses can play a vital role in improving the quality use of antibiotics. We know that surveys have already been conducted to explore the knowledge, attitude, and practices of nurses about antibiotic use, stewardship, and resistance in different parts of the world. ${ }^{55,56} \mathrm{We}$ are also aware of a study on knowledge and practices of physicians and pharmacists reported from Pakistan. ${ }^{57}$ In this country, the condition of antibiotic resistance is bleak. ${ }^{57}$ However, due to the growing economic burden of antibiotic resistance, all health care professionals must work together to benefit patients maximally. This qualitative study provides a valuable snapshot of the current practices of nurses and focuses on understanding the underlying factors of growing antibiotic resistance in Quetta, Pakistan. To the best of our knowledge, this is the first time such an in-depth study has been conducted among nurses to guide future policies, which is vital as Pakistan is in process of developing its national action plan on AMR. ${ }^{58,59}$ Therefore, this is among the first studies in Pakistan to seek the useful information about the understanding, perception, and practices of nurses about antibiotic use and resistance, besides, it also explores the views and concerns on contributing factors.

Although, findings of the current study showed a positive perception of nurses regarding antibiotics, certain misapprehensions towards antibiotic resistance were also reported. These results are promising as positive perception is often associated well with better clinical practices. However, these findings also highlighted that there are opportunities to improve continuous knowledge about antibiotic stewardship among nurses. Results of this qualitative study revealed that the use of broad-spectrum antibiotics is widespread and nurses are aware and concerned about injudicious use of antibiotics, similar to the findings of previous surveys conducted in resident physicians and faculty. ${ }^{60,61}$ Interviewees agreed that habitual prescribing practices of broad-spectrum antibiotics lead to irrational use as discussed in other studies. ${ }^{62,63}$ In such situations, outcome-based medical education like frequent awareness campaigns and continuing medical education could be an effective way to bridge the gap between knowledge and practice. The interviewees also revealed that the reasons for the irrational use of antibiotics are the 
limited number of available antibiotics in the public healthcare sector, and patient load along with the demand for antibiotics by a patient. Results of the qualitative interviews also exposed that patient's satisfaction was one of the reasons for irrational antibiotic use similar to another study. $^{64}$

In this study, nurses agreed that the situation of antibiotic resistance is very alarming as few infectious microbes are resistant to almost every drug regime as described in another study. ${ }^{65}$ Interviewees exposed that antibiotics use surveillance and prescribing guidelines are not in place and antibiotics were prescribed by the doctors based on their experience similar to findings of a study conducted in Iran. ${ }^{63}$ On the other hand, results of studies conducted in European countries and Saudi Arabia revealed that institutional antibiotic prescribing guidelines are present to rationalize the use of antibiotics in hospitals. $^{66,67}$ Lack of support from the Ministry of Health, Pakistan for such programs is another contributing factor for antibiotic resistance while in developed countries like the American government play significant roles in implementation of antimicrobial stewardship programs considering it a global threat. ${ }^{68}$ It is encouraging to note that nurses agreed that antibiotics should never be purchased as over-the-counter drugs which are in line with other published studies which also reported the same point. $^{69-71}$ The interviewees also stressed the need for strict legislation by drug regulatory authorities to stop over-the-counter use of antibiotics through the national action plan of Pakistan on antibiotic resistance. ${ }^{57}$

\section{Conclusion}

Limited availability of antibiotics, lack of sensitivity testing and habitual prescribing of broad-spectrum antibiotics was identified as key barriers while addressing quality use of antibiotics. Importantly, nurses too highlighted possible solutions (strict legislation by drug regulatory authorities to stop over-the-counter use of antibiotics) to address the issue of irrational antibiotic use and the development of antibiotic resistance. Consequently, the findings of this study should be disseminated and must be considered by the practitioners while prescribing antibiotics. Likewise, we also recommend policymakers to consider these finding when designing procedures in promoting quality use of antibiotics and minimizing the development of antibiotic resistance.

\section{Limitations and Recommendations}

This qualitative study does have certain limitations. Firstly, the sampling approach of including interviewees limits the extrapolation of results because those who did not participate in this survey may have different views. Therefore, our findings cannot be generalized to the whole of Pakistan. It only depicts the understanding, perception, and practices of nurses of the City of Balochistan. Secondly, as with most studies, respondents might have given socially desirable answers rather than their actual opinions or practices. Nonetheless, several obvious implications flow from the findings to ensure rational use of antibiotics because this study addresses the significant issues of antibiotic use and resistance among nurses in whom much research has not been conducted in the past. This population in Pakistan remains to be untouched, stemming from the fact nurses are closely associated with physicians.

\section{Acknowledgments}

The authors wish to acknowledge the nurses for their participation. We are also grateful to the hospital administration for their continuous support.

\section{Disclosure}

The authors have no conflict of interest to disclose. No funding was received for this study.

\section{References}

1. Lobanovska M, Pilla G. Penicillin's discovery and antibiotic resistance: lessons for the future? Yale J Biol Med. 2017;90(1):135-145.

2. Fernandes P. Antibacterial discovery and development- the failure of success? Nat Biotechnol. 2006;24(12):1497-1503. doi:10.1038/ nbt1206-1497

3. Boman HG. Antibacterial peptides: basic facts and emerging concepts. $J \quad$ Intern Med. 2003;254(3):197-215. doi:10.1046/j.13652796.2003.01228.x

4. World Health Organization. Antibiotic resistance. Available from: https://www.who.int/news-room/fact-sheets/detail/antibioticresistance. Accessed May 7, 2021.

5. Malik B, Bhattacharyya S. Antibiotic drug-resistance as a complex system driven by socio-economic growth and antibiotic misuse. Sci Rep. 2019;9(1):1-12. doi:10.1038/s41598-018-37186-2

6. Chandler CI. Current accounts of antimicrobial resistance: stabilisation, individualisation and antibiotics as infrastructure. Palgrave Commun. 2019;5(1):1-13. doi:10.1057/s41599-019-0263-4

7. Chopra I, Roberts M. Tetracycline antibiotics: mode of action, applications, molecular biology, and epidemiology of bacterial resistance. Microbiol Mol Biol Rev. 2001;65(2):232-260. doi:10.1128/ MMBR.65.2.232-260.2001

8. Davies J, Davies D. Origins and evolution of antibiotic resistance. Microbiol Mol Biol Rev. 2010;74(3):417-433. doi:10.1128/ MMBR.00016-10 
9. Wellington EM, Boxall AB, Cross $\mathrm{P}$, et al. The role of the natural environment in the emergence of antibiotic resistance in Gram-negative bacteria. Lancet Infect Dis. 2013;13(2):155-165. doi:10.1016/S1473-3099(12)70317-1

10. Wang X, Peng D, Wang W, Xu Y, Zhou X, Hesketh T. Massive misuse of antibiotics by university students in all regions of China: implications for national policy. Int J Antimicrob Agents. 2017;50 (3):441-446. doi:10.1016/j.ijantimicag.2017.04.009

11. Saleem Z, Saeed H, Ahmad M, et al. Antibiotic self-prescribing trends, experiences and attitudes in upper respiratory tract infection among pharmacy and non-pharmacy students: a Study from Lahore. PLoS One. 2016;11(2):e0149929. doi:10.1371/journal.pone.0149929

12. Zhang R, Eggleston K, Rotimi V, Zeckhauser R. Health. Antibiotic resistance as a global threat: evidence from China, Kuwait and the United States. Global Health. 2006;2(1):6. doi:10.1186/1744-86032-6

13. Saleem Z, Hassali MA. Travellers take heed: outbreak of extensively drug resistant (XDR) typhoid fever in Pakistan and a warning from the US CDC. Travel Med Infect Dis. 2019;27:127. doi:10.1016/j. tmaid.2018.10.013

14. Van Boeckel TP, Gandra S, Ashok A, et al. Global antibiotic consumption 2000 to 2010: an analysis of national pharmaceutical sales data. Lancet Infect Dis. 2014;14(8):742-750. doi:10.1016/S14733099(14)70780-7

15. O'Neill J. Tackling drug-resistant infections globally: final report and recommendations. London: HM Government and Wellcome Trust. Review on Antimicrobial Resistance, chaired by Jim O’Neill; 2016. Available from: https://amr-review.org/sites/default/files/160518 Final\%20paper_with\%20cover.pdf. Accessed May 10, 2021.

16. Reynolds L, McKee M. Factors influencing antibiotic prescribing in China: an exploratory analysis. Health Policy (New York). 2009;90 (1):32-36. doi:10.1016/j.healthpol.2008.09.002

17. Byrne MK, Miellet S, McGlinn A, et al. The drivers of antibiotic use and misuse: the development and investigation of a theory driven community measure. BMC Public Health. 2019;19(1):1-11. doi:10.1186/s12889-019-7796-8

18. Lin L, Sun R, Yao T, Zhou X, Harbarth S. Factors influencing inappropriate use of antibiotics in outpatient and community settings in China: a mixed-methods systematic review. BMJ Glob Health 2020;5(11):e003599. doi:10.1136/bmjgh-2020-003599

19. Nair M, Tripathi S, Mazumdar S, et al. Knowledge, attitudes, and practices related to antibiotic use in Paschim Bardhaman District: a survey of healthcare providers in West Bengal, India. PLoS One. 2019;14(5):e0217818. doi:10.1371/journal.pone.0217818

20. Alghamdi S, Atef-Shebl N, Aslanpour Z, Berrou I. Barriers to implementing antimicrobial stewardship programmes in three Saudi hospitals: evidence from a qualitative study. $J$ Glob Antimicrob Resist. 2019;18:284-290. doi:10.1016/j.jgar.2019.01.031

21. Bennadi D. Self-medication: a current challenge. J Basic Clin Pharm. 2013;5(1):19. doi:10.4103/0976-0105.128253

22. Rather IA, Kim BC, Bajpai VK, Park YH. Self-medication and antibiotic resistance: crisis, current challenges, and prevention. Saudi J Biol Sci. 2017;24(4):808-812. doi:10.1016/j.sjbs.2017.01.004

23. Lum EP, Page K, Whitty JA, Doust J, Graves N. Antibiotic prescribing in primary healthcare: dominant factors and trade-offs in decision-making. Infect Dis Health. 2018;23(2):74-86. doi:10.1016/ j.idh.2017.12.002

24. Cole A. GPs feel pressurised to prescribe unnecessary antibiotics, survey finds. $B r$ Med J. 2014;349:g5238. doi:10.1136/bmj.g5238

25. Kümmerer $\mathrm{K}$. The presence of pharmaceuticals in the environment due to human use-present knowledge and future challenges. J Environ Manage. 2009;90(8):2354-2366. doi:10.1016/j.jenvman.2009.01.023

26. Kitzinger J. Qualitative research: introducing focus groups. Br Med J. 1995;311(7000):299-302. doi:10.1136/bmj.311.7000.299

27. Berg BL, Lune H, Lune H. Qualitative Research Methods for the Social Sciences. Vol. 5. Boston MA: Pearson; 2004.
28. Krueger RA. Focus Groups: A Practical Guide for Applied Research. Sage. Inc; 2009.

29. Stewart DW, Shamdasani PN. Focus Groups: Theory and Practice. Vol. 20. Sage Publications; 2014.

30. Mullen PD, Reynolds R. The potential of grounded theory for health education research: linking theory and practice. Health Educ Behav. 1978;6(3):280-294.

31. Entwistle VA, Renfrew MJ, Yearley S, Forrester J, Lamont T. Lay perspectives: advantages for health research. Br Med J. 1998;316 (7129):463-466. doi:10.1136/bmj.316.7129.463

32. Shahzad F, Saleem F, Iqbal Q, et al. A cross-sectional assessment of health literacy among hypertensive community of Quetta City, Pakistan. Biomed J Sci Tech Res. 2018;4:1-9.

33. Brace-Govan J. Issues in snowball sampling: the lawyer, the model and ethics. Qual Res J. 2004;4(1):52-60.

34. Krockow E, Colman A, Chattoe-Brown E, et al. Balancing the risks to individual and society: a systematic review and synthesis of qualitative research on antibiotic prescribing behaviour in hospitals. J Hosp Infect. 2019;101(4):428-439. doi:10.1016/j.jhin.2018.08.007

35. Moongtui W, Picheansathian W, Senaratana W. Role of nurses in prevention of antimicrobial resistance. In: Regional Health Forum; WHO South-East Asia Region. Special Issue on Antimicrobial Resistance in South-East Asia. World Health Organization; 2011:104-111. Available from: https://apps.who.int/iris/bitstream/handle/10665/205782/B4704. pdf? sequence=1\&isAllowed=y. Accessed February 15, 2021

36. Nair M, Tripathi S, Mazumdar S, et al. "Without antibiotics, I cannot treat": a qualitative study of antibiotic use in Paschim Bardhaman district of West Bengal, India. PLoS One. 2019;14(6):e0219002. doi:10.1371/journal.pone.0219002

37. Asante KP, Boamah EA, Abdulai MA, et al. Knowledge of antibiotic resistance and antibiotic prescription practices among prescribers in the Brong Ahafo Region of Ghana; a cross-sectional study. BMC Health Serv Res. 2017;17(1):422. doi:10.1186/s12913-017-2365-2

38. Brooks L, Shaw A, Sharp D, Hay AD. Towards a better understanding of patients' perspectives of antibiotic resistance and MRSA: a qualitative study. Fam Pract. 2008;25(5):341-348. doi:10.1093/ fampra/cmn037

39. Kallio H, Pietilä AM, Johnson M, Kangasniemi M. Systematic methodological review: developing a framework for a qualitative semistructured interview guide. J Adv Nurs. 2016;72(12):2954-2965. doi:10.1111/jan.13031

40. Morris A. A Practical Introduction to In-Depth Interviewing. Sage; 2015.

41. Voutsina C. A practical introduction to in-depth interviewing. Int $J$ Res Method Educ. 2018;41(1):123-124. doi:10.1080/ 1743727X.2017.1419693

42. Wild D, Grove A, Martin M, et al. Principles of good practice for the translation and cultural adaptation process for patient-reported outcomes (PRO) measures: report of the ISPOR Task Force for Translation and Cultural Adaptation. Value Health. 2005;8 (2):94-104. doi:10.1111/j.1524-4733.2005.04054.x

43. Saunders B, Sim J, Kingstone T, et al. Saturation in qualitative research: exploring its conceptualization and operationalization. Qual Quant. 2018;52(4):1893-1907. doi:10.1007/s11135-0170574-8

44. Nelson J. Using conceptual depth criteria: addressing the challenge of reaching saturation in qualitative research. Qual Res J. 2017;17 (5):554-570. doi:10.1177/1468794116679873

45. Guest G, MacQueen KM, Namey EE. Introduction to Applied Thematic Analysis. Sage; 2012:20.

46. Anderson R. Intuitive inquiry: an epistemology of the heart for scientific inquiry. J Humanist Psychol. 2004;32(4):307-341. doi:10.1080/08873267.2004.9961758

47. Vaismoradi M, Turunen H, Bondas T. Content analysis and thematic analysis: implications for conducting a qualitative descriptive study. Nurs Health Sci. 2013;15(3):398-405. doi:10.1111/nhs.12048 
48. Edhlund B, McDougall A. Nvivo 12 Essentials. Stallarholmen, Sweden: Form \& Kunskap AB; 2019.

49. Lehane E, Leahy-Warren P, O'Riorda C, et al. Evidence-based practice education for healthcare professions: an expert view. BMJ Evid Based Med. 2019;24(3):103-108. doi:10.1136/bmjebm-2018-111019

50. Stevens K. The impact of evidence-based practice in nursing and the next big ideas. Online J Issues Nurs. 2013;18(2):4.

51. Krau SD. The utilization of evidenced-based practice in nursing: some important considerations. Nurs Clin N Am. 2014;49(4):xi-xii.

52. Khalid F, Abbasi AN. Challenges faced by Pakistani healthcare system: clinician's perspective. $J$ Coll Physicians Surg Pak. 2018;28(12):899-901.

53. Tong S, Pan J, Lu S, Tang J. Patient compliance with antimicrobial drugs: a Chinese survey. Am J Infect Control. 2018;46(4):e25-e9. doi:10.1016/j.ajic.2018.01.008

54. Zanichelli V, Tebano G, Gyssens I, et al. Patient-related determinants of antibiotic use: a systematic review. Clin Microbiol Infect. 2019;25 (1):48-53. doi:10.1016/j.cmi.2018.04.031

55. Abbas S, Lee K, Pakyz A, et al. Knowledge, attitudes, and practices of bedside nursing staff regarding antibiotic stewardship: a cross-sectional study. Am J Infect Control. 2019;47(3):230-233. doi:10.1016/j.ajic.2018.09.008

56. Abbo L, Smith L, Pereyra M, Wyckoff M, Hooton TM. Nurse practitioners' attitudes, perceptions, and knowledge about antimicrobial stewardship. J Nurse Pract. 2012;8(5):370-376. doi:10.1016/j. nurpra.2012.01.023

57. Saleem Z, Hassali MA, Hashmi FK. Pakistan's national action plan for antimicrobial resistance: translating ideas into reality. Lancet Infect Dis. 2018;18(10):1066-1067. doi:10.1016/S1473-3099(18)30516-4

58. The Express Tribune. Antimicrobial resistance: health ministry drafts a 'national action plan'. Available from: https://tribune.com.pk/story/ 1345481/antimicrobial-resistance-health-ministry-drafts-nationalaction-plan/. Accessed April 2, 2021.

59. Ministry of National Health Services Regulations and Coordination. Antimicrobial Resistance National Action Plan Pakistan. Ministry of National Health Services Regulations \& Coordination, Government of Pakistan; 2017. Available from: https://www.nih.org.pk/amrnational-action-plan-pakistan/. Accessed March 10, 2021.

60. Guerra CM, Pereira CAP, Neto ARN, Cardo DM, Correa L. Physicians' perceptions, beliefs, attitudes, and knowledge concerning antimicrobial resistance in a Brazilian teaching hospital. Infect Control Hosp Epidemiol. 2007;28(12):1411-1414. doi:10.1086/523278

61. Srinivasan A, Song X, Richards A, Sinkowitz-Cochran R, Cardo D, Rand C. A survey of knowledge, attitudes, and beliefs of house staff physicians from various specialties concerning antimicrobial use and resistance. Arch Intern Med. 2004;164(13):1451-1456. doi:10.1001/ archinte.164.13.1451
62. Om C, Daily F, Vlieghe E, McLaughlin JC, McLaws M-L. "If it'sa broad spectrum, it can shoot better": inappropriate antibiotic prescribing in Cambodia. Antimicrob Resist Infect Control. 2016;5(1):58. doi:10.1186/s13756-016-0159-7

63. Hashemi S, Nasrollah A, Rajabi M. Irrational antibiotic prescribing: a local issue or global concern? Excli J. 2013;12:384-395.

64. Tillekeratne LG, Bodinayake CK, Dabrera T, et al. Antibiotic overuse for acute respiratory tract infections in Sri Lanka: a qualitative study of outpatients and their physicians. BMC Fam Pract. 2017;18(1):37. doi:10.1186/s12875-017-0619-z

65. Byarugaba D. Antimicrobial resistance in developing countries and responsible risk factors. Int $J$ Antimicrob Agents. 2004;24 (2):105-110. doi:10.1016/j.ijantimicag.2004.02.015

66. Al-Homaidan HT, Barrimah IE. Physicians' knowledge, expectations, and practice regarding antibiotic use in primary health care. Int J Health Sci. 2018;12(3):18-24.

67. Beović B, Doušak M, Pulcini C, et al. Young doctors' perspectives on antibiotic use and resistance: a multinational and inter-specialty cross-sectional European Society of Clinical Microbiology and Infectious Diseases (ESCMID) survey. J Antimicrob Chemother. 2019;74(12):3611-3618. doi:10.1093/jac/dkz375

68. Dellit TH, Owens RC, McGowan JE, et al. Infectious Diseases Society of America and the Society for Healthcare Epidemiology of America guidelines for developing an institutional program to enhance antimicrobial stewardship. Clin Infect Dis. 2007;44 (2):159-177. doi:10.1086/510393

69. Chang J, Ye D, Lv B, et al. Sale of antibiotics without a prescription at community pharmacies in urban China: a multicentre cross-sectional survey. $J$ Antimicrob Chemother. 2017;72 (4): $1235-1242$.

70. Saleem Z, Hassali MA, Hashmi FK, Godman B, Saleem F. Antimicrobial dispensing practices and determinants of antimicrobial resistance: a qualitative study among community pharmacists in Pakistan. Fam Med Community Health. 2019;7:e000138. doi:10.1136/fmch-2019-000138

71. Saleem Z, Hassali MA, Godman B, Hashmi FK, Saleem F. Antimicrobial prescribing and determinants of antimicrobial resistance: a qualitative study among physicians in Pakistan. Int $J$ Clin Pharm. 2019;41(5):1348-1358. doi:10.1007/s11096-019-00875-7

\section{Publish your work in this journal}

The Journal of Multidisciplinary Healthcare is an international, peerreviewed open-access journal that aims to represent and publish research in healthcare areas delivered by practitioners of different disciplines. This includes studies and reviews conducted by multidisciplinary teams as well as research which evaluates the results or conduct of such teams or healthcare processes in general. The journal covers a very wide range of areas and welcomes submissions from practitioners at all levels, from all over the world. The manuscript management system is completely online and includes a very quick and fair peer-review system. Visit http://www.dovepress.com/testimonials. php to read real quotes from published authors. 